\title{
Restraint of Monkeys for Craniofacial Research
}

\author{
JAMES A. MC NAMARA, JR. \\ Department of Anatomy and Center for Human Growth and Development, \\ University of Michigan, Ann Arbor, Michigan 48104, USA
}

Because of the aggressive behavior of nonhuman primates, experimentation on unanesthetized monkeys requires the use of a restraint system. This paper reports the development of a primate restraining system that maximizes short-term fixation and standardization of head position; this system also provides moderate limitation of body movement. The device consists of a primate chair, which was modified from a basic design (Moody et al, Behav Res Meth and Instr 2:180-182, 1970), and a head holder mounted on the chair.

The parts of the restraining chair are a metal base with rubber casters, a seating grid, five horizontal acrylic plates, and a chest plate (illustration). The Plexiglas chest plate is parallel to the $18 \times 18$ inch base and it is attached to four vertical aluminum rods that are 36 inches high. A $5 \times 10$ inch slot, which is cut into the chest plate, enables the monkey to be positioned in the chair. The chest plate restricts upper arm movement so that the animal cannot interfere with experimentation in the facial region. The seating grid is a network of six aluminum rods that are fastened to each other and to the vertical posts by adjustable lattice connectors. These connectors also are used to mount the rods that are attached to the horizontal plates. These contour Plexiglas plates provide further restraint and they support the trunk of the animal.

The head-restraining device is connected to the four vertical supports by four 12 inch, diagonally oriented aluminum rods that are attached to the center support post of the headholder. Suspended from the center support post are three parallel rods, a center screw, and two lateral rods. The anterior and posterior components of the head clamp are connected to the parts suspended from the center support post. The clamp is designed to fit over the supraorbital ridges and the occipital region; these regions are relatively free from orofacial muscle attachment. This device permits fixation of head orientation without interference in the normal functional patterns of the masticatory and facial muscles.

Neuromuscular studies of the unanesthetized

This study was supported in part by USPHS Grant HD-02272 and DE-43120.

Additional information available on request to author.

Received for publication May 30, 1972.

The author thanks T. Kuroda, M. L. Riolo, D. E. Ellison, S. Everhardus, and E. R. Gooding for their technical assistance. monkey have long been thought difficult, if not impossible, because of the animal's excitability and aggressive behavior. This restraining system has proved to be useful in our laboratory for routine electromyography of the facial region of the monkey. Normal functional patterns such as chewing apples and sugar and swallowing water are elicited easily. The restraining system also can be used in studies of laryngeal function, of eye movement, and in auditory and neurologic investigations where positive head fixation is desirable.

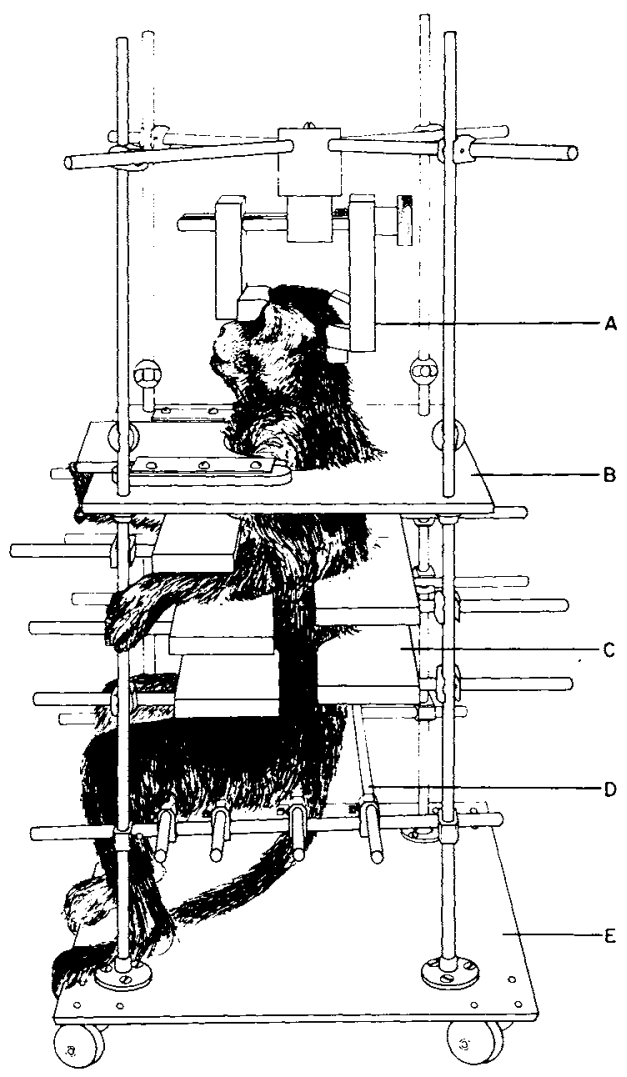

Restraint system: $A$, head holder; $B$, chest plate; $C$, horizontal plates; $D$, seating grid; $E$, base plate with rubber casters. 